\title{
Calibration procedures and first dataset of Southern Ocean chlorophyll $a$ profiles collected by elephant seals equipped with a newly developed CTD-fluorescence tags
}

\author{
C. Guinet ${ }^{1}$, X. Xing ${ }^{2,3,4}$, E. Walker ${ }^{5}$, P. Monestiez ${ }^{5}$, S. Marchand ${ }^{6}$, B. Picard ${ }^{1}$, T. Jaud ${ }^{1}$, M. Authier ${ }^{1}$, \\ C. Cotté ${ }^{1,7}$, A. C. Dragon ${ }^{1}$, E. Diamond ${ }^{2,3}$, D. Antoine ${ }^{2,3}$, P. Lovell ${ }^{8}$, S. Blain ${ }^{9,10}$, F. D'Ortenzio ${ }^{2,3}$, and \\ H. Claustre ${ }^{2,3}$ \\ ${ }^{1}$ Centre d'Etudes Biologiques de Chizé-CNRS, Villiers en Bois, France \\ ${ }^{2}$ Laboratoire d'Océanographie de Villefranche, Villefranche-sur-Mer, France \\ ${ }^{3}$ Université Pierre et Marie Curie (Paris-6), Unité Mixte de Recherche 7093, Laboratoire d'Océanographie de \\ Villefranche, Villefranche-sur-Mer, France \\ ${ }^{4}$ Ocean University of China, Qingdao, China \\ ${ }^{5}$ Unité Biostatistique et Processus Spatiaux-INRA, Avignon, France \\ ${ }^{6}$ Muséum national d'histoire naturelle, DMPA USM 402/LOCEAN, Paris, France \\ ${ }^{7}$ Université Pierre et Marie Curie (Paris-6), DMPA USM 402/LOCEAN, Paris, France \\ ${ }^{8}$ Sea Mammal Research Unit, University of St. Andrews, St. Andrews, Scotland \\ ${ }^{9}$ Laboratoire d'Océanographie Microbienne, Université Paris VI, Banyuls sur mer, France \\ ${ }^{10}$ Université Pierre et Marie Curie (Paris-6), Unité Mixte de Recherche 7621, Laboratoire d'Océanographie \\ Microbienne, Banyuls-sur-Mer, France \\ Correspondence to: C. Guinet (guinet@ cebc.cnrs.fr)
}

\begin{abstract}
Received: 21 June 2012 - Published in Earth Syst. Sci. Data Discuss.: 23 August 2012
Revised: 11 December 2012 - Accepted: 11 December 2012 - Published: 4 February 2013
\end{abstract}

\begin{abstract}
In situ observation of the marine environment has traditionally relied on ship-based platforms. The obvious consequence is that physical and biogeochemical properties have been dramatically undersampled, especially in the remote Southern Ocean (SO). The difficulty in obtaining in situ data represents the major limitations to our understanding, and interpretation of the coupling between physical forcing and the biogeochemical response. Southern elephant seals (Mirounga leonina) equipped with a new generation of oceanographic sensors can measure ocean structure in regions and seasons rarely observed with traditional oceanographic platforms. Over the last few years, seals have allowed for a considerable increase in temperature and salinity profiles from the SO, but we were still lacking information on the spatiotemporal variation of phytoplankton concentration. This information is critical to assess how the biological productivity of the SO, with direct consequences on the amount of $\mathrm{CO}_{2}$ "fixed" by the biological pump, will respond to global warming. In this research programme, we use an innovative sampling fluorescence approach to quantify phytoplankton concentration at sea. For the first time, a low energy consumption fluorometer was added to Argos CTD-SRDL tags, and these novel instruments were deployed on 27 southern elephant seals between 25 December 2007 and the 4 February 2011. As many as 3388 fluorescence profiles associated with temperature and salinity measurements were thereby collected from a vast sector of the Southern Indian Ocean. This paper addresses the calibration issue of the fluorometer before being deployed on elephant seals and presents the first results obtained for the Indian sector of the Southern Ocean. This in situ system is implemented in synergy with satellite ocean colour radiometry. Satellite-derived data is limited to the surface layer and is restricted over the SO by extensive cloud cover. However, with the addition of these new tags, we are able to assess the 3-dimension distribution of phytoplankton concentration by foraging southern elephant seals. This approach reveals that for the Indian sector of the SO, the surface chlorophyll $a(\mathrm{chl} a)$ concentrations provided by MODIS were underestimated by a factor 2 compared to chl $a$ concentrations estimated from HPLC corrected in situ fluorescence measurements. The scientific outcomes of this programme include an improved understanding of both the present state and variability in ocean biology, and the accompanying biogeochemistry, as well as the delivery of real-time and open-access data to scientists (doi:10.7491/MEMO.1).
\end{abstract}




\section{Introduction}

Polar marine ecosystems, and in particular the Southern Ocean (SO hereafter), are among the most vulnerable ecosystems to climate change. However, there is conflicting evidence on how the biological productivity of these Polar Oceans will respond to global warming. The SO plays an important role in the carbon cycle and it is one of the largest sink for anthropogenic $\mathrm{CO}_{2}$ through the formation of deep water around Antarctica and intermediate water in the vicinity of the subantarctic zone (Caldeira et al., 2000; Lo Monaco et al., 2005). Furthermore, by contributing to roughly half of the biosphere's primary production, photosynthesis by oceanic phytoplankton is a vital link between living and inorganic stocks of carbon (Field et al., 1998; Berhenfeld et al., 2006), but our current understanding of the variability of SO's primary productivity is hampered by the lack of in situ observations available for this logistically difficult region, and much of the existing observations are heavily biased towards the austral summer.

Furthermore, the degree of confidence for primary production derived from satellite-based estimates of phytoplankton biomass is still debated. This is especially true in SO, where satellite measurements tend to under-estimate chlorophyll $a$ (chl $a$ hereafter) concentrations (Dierssen and Smith, 2000; Holm-Hansen et al., 2004; Garcia et al., 2005; Dierssen, 2010; Kahru and Mitchell, 2010). Satellites scan the sea surface and are unable to provide subsurface chlorophyll profiles. Deep fluorescence maxima have been found within the frontal zone of the Antarctic Circum Current (ACC hereafter, Quéguiner and Brzezinski, 2002; Holm-Hansen et al., 2004) or in the vicinity of the ice edge (Waite and Nodder, 2001). Persistent cloud cover and fragmented sea-ice also constitute towards a major limitation of satellite ocean colour measurements in the SO (Arrigo et al., 1998; Buesseler et al., 2003).

Evaluation of the distribution of chl $a$ throughout the water column is one of the most important biological parameters in the ocean because it is an indicator of the spatial and temporal variability of primary productivity (Behrenfeld and Falkowski, 1997). The limitations of satellite assessments of primary production combined with a lack of primary productivity measurements in the field requires to complement remotely sensed ocean colour data with year-round surveys of the in situ optics as well as the physical oceanographic measurements for a description of spatial (horizontal and vertical) and temporal (seasonal, inter-annual) distribution of phytoplankton, but also give insights on its advection and fate. In turn, this data will contribute to our understanding of how primary production within SO may respond to climatic changes.

Subsurface chl a measurements are traditionally performed from research vessels, using profiling fluorometers and water samples collected by Niskin bottles. Alternatively, chl $a$ profiles can be obtained from fluorometers deployed on fixed moorings or autonomous platforms like Argo floats
(Roemmich et al., 2004), or autonomous underwater vehicles (Yu et al., 2002). Rapid technological advances in ocean observation have nevertheless been achieved during the last decade, particularly with respect to physical climate variables. Developing such in situ observation systems is an essential step towards a better understanding of biogeochemical cycles and ecosystem dynamics, especially at spatial and temporal scales that have been unexplored until now. However, with regard to the carbon cycle, the establishment of in situ observing systems in the under-sampled SO remains challenging due to its remoteness, harsh weather conditions and the presence of sea-ice.

Here we present the development of an original synergy between biologist's efforts to understand the marine life of top predators, physical and biogeochemical oceanographic studies through development of new bio-logging devices deployed on southern elephant seals (Mirounga leonina), SES hereafter. This device incorporates high accuracy temperature and salinity sensors, as well as a fluorometer and provides a range of new behavioural and physiological data on free ranging marine animals for biologists, while simultaneously gathering vertical profiles of temperature, salinity and fluorescence for oceanographers. Profiles sampled in the remote SO are of great interest as they can fill a niche within the ocean observing system, where such measurements are lacking (e.g., Charrassin et al., 2008; Nicholls et al., 2008; Roquet et al., 2009; Wunch et al., 2009). One important aspect of this methodology is the near real-time delivery of CTD-Fluo profiles using the Argos satellite system (Argos, 1996). SESs provide an ideal "platform" for such investigation as they dive nearly continuously and at great depths (Hindell et al., 1991). Moreover, they undertake long foraging trips each year, exploring large areas of the SO (Biuw et al., 2007).

However, to make most of the use of these fluorescence data, it is essential to develop effective means for calibration, quality control and postprocessing to provide a consistent dataset to oceanographers and for climatologies. Therefore, the first objective of this paper is to report the calibration and the profile qualification procedure on a unique 3yr fluorescence dataset collected by SES within the Indian sector of the Southern Ocean. From this data, we will assess how in situ measurements compare with surface chl $a$ concentration measured by ocean colour satellites. This new approach allows sustained acquisition of chl $a$ fluorescence profiles (proxy for chl $a$ concentration) in areas where data scarcity is the rule and how they complement satellite ocean colour data.

\section{Materials and methods}

\subsection{Instrumentation}

A thorough technical description of CTD-SRDLs can be found in Boehme et al. (2009), which we briefly summarise 
here (see also Fedak et al., 2002). CTD-Fluoro-SRDLs have been designed as miniaturised platforms to record behavioural data and log in situ CTD profiles. They can be deployed on a range of marine mammals (e.g., Lydersen et al., 2002; Boehme et al., 2008; Nicholls et al., 2008; Roquet et al., 2009). The devices contain (1) a Platform Terminal Transmitter (PTT) to transmit compressed data through the Argos satellite system, (2) a micro-controller coordinates the different functions e.g., sensor data acquisition (data processing and transmission based on the internal setup and energy budget, Boehme et al. (2009) and (3) a miniaturised CTD (Valeport LTD, Totnes, UK).

The specifications of the miniaturised CTD (Valeport Ltd, Totnes, UK) result from a trade-off between the need for miniaturisation, energy consumption, stability and sensor performance. The pressure measurements are made by a Keller series-PA7 piezoresistive pressure transducer1 (Keller AG, $\mathrm{CH}$ ) with a given accuracy of better than $1 \%$ of the fullscale reading ( \pm 20 dbar at 2000 dbar). However, laboratory experiments have shown a performance of better than $0.25 \%$ of the actual reading (Boehme et al., 2009). The temperature probe is a fast response Platinum Resistance Thermometer (PRT) made by Valeport (range: $-5^{\circ} \mathrm{C}$ to $+35^{\circ} \mathrm{C}$, accuracy: $\pm 0.005^{\circ} \mathrm{C}$, time constant: $0.7 \mathrm{~s}$ ) and an inductive conductivity sensor by Valeport (range: 0 to $80 \mathrm{mS} \mathrm{cm}^{-1}$, accuracy: better than $\left.\pm 0.01 \mathrm{mS} \mathrm{cm}^{-1}\right)$.

\section{Implementation of a fluorometer to estimate chl $a$ concentration}

In vivo fluorescence $F$ is a widely used technique to estimate chl $a$ concentration in aquatic environments and can be expressed as:

$F=E a^{*}[\operatorname{chl} a] \varphi_{\mathrm{f}}$

Where $E$ (mole quanta $\mathrm{m}^{-2} \mathrm{~s}^{-1}$ ) is the intensity of the exciting source, $a^{*}$ is the chl-specific absorption coefficient $\left(\mathrm{m}^{2} \mathrm{mg}[\mathrm{chl} a]^{-1}\right)$ where $[\mathrm{chl} a]$ is the chl $a$ concentration ([chl- $a$ ] hereafter) $\left(\mathrm{mg} \mathrm{chl} a \mathrm{~m}^{-3}\right)$ and $\varphi_{\mathrm{f}}$ is the quantum yield for fluorescence [mole of emitted quanta (mole absorbed quanta $\left.\left.^{-1}\right)\right]$.

The fluorescence-chl $a$ relationship for a given fluorometer varies according to environmental conditions such as the phytoplankton taxonomic composition and physiological adaptative mechanisms (e.g., Falkowski and Kolber, 1995; Babin et al., 1996, 2008).

The Cyclops 7 is a compact cylinder $(110 \times 25 \mathrm{~mm}$ after removal of the end cap), low energy consumption single channel fuorescence detector that can be used for many different applications. It delivers a voltage output that is proportional to the concentration of the chl $a$ particle, or compound of interest. For chl $a$ detection a $460 \mathrm{~nm}$ exciting wavelength and a $620-715 \mathrm{~nm}$ fluorescence detection photodiode are used. According to Turner Design specifications the minimum detection limit is $0.025 \mu \mathrm{g} \mathrm{L}^{-1}$ of chl $a$. The Cyclops 7 can be set on a different level of sensitivity for chl $a$ detection allowing detection of maximum chl $a$ concentration ranging generally from low (i.e., detection range $0-500 \mu \mathrm{g} \mathrm{L}^{-1}$ ) to medium $\left(0-50 \mu \mathrm{g} \mathrm{L}^{-1}\right)$ and high $\left(0-5 \mu \mathrm{g} \mathrm{L}^{-1}\right)$ sensitivities. For our application according to chl $a$ climatologies available, the initial detection range was set between $0-2.5 \mu \mathrm{g} \mathrm{L}^{-1}$, a range well matching the chl $a$ concentration generally encountered within the oceanic waters of the SO (Reynolds et al., 2001; Marrari et al., 2006; Uitz et al., 2009).

The Cyclops 7 was integrated in a new CTD-Fluo Satellite Relay Data Loggers (Tags hereafter). They were built by the Sea Mammal Research Unit (SMRU) (University of St. Andrews, Scotland). Fluorescence was sampled continuously between the surface and $180 \mathrm{~m}$. As Argos messages are restricted in length, we had to reduce the resolution of fluorescence data. Therefore, values were averaged for eighteen $10 \mathrm{~m}$ vertical sections. For each section the mean fluorescence value was allocated to the mid-depth point of the corresponding section.

Fluorometer calibrations, relying essentially on chl $a$ solutions or on phytoplankton cultures, are generally provided by manufacturers. Most of the time these calibrations are established for large range of chl $a$ concentrations not always representative of in situ ones. Therefore, it is highly desirable to confirm or adjust through in situ calibration on natural samples (see Xing et al., 2012). As part of this programme, a thorough calibration and testing procedure was undertaken for the CTD-Fluo SRDL. Pre-deployment calibrations of the tags and at-sea validating tests were conducted prior to SES deployment. This procedure was followed for most deployments in this study. Before being taken into the field, devices were calibrated at Valeport, Service Hydrographique de la Marine (Brest, France), and had temperature $(T)$ and conductivity $(C)$ resolutions of $0.001{ }^{\circ} \mathrm{C}$ and $0.002 \mathrm{mS} \mathrm{cm}^{-1}$, respectively (see Roquet et al., 2011 for details).

\subsection{Calibration procedure}

The fluoremeters were inter-calibrated by implementing a Bayesian procedure using all information available regarding predeployment tests as well as post-deployment information collected.

\subsubsection{Fluorometer inter-calibration and conversion in chl $a$ concentration}

\section{Pre-deployment tests}

Five consecutive sessions of CTD-Fluo SRDL deployments on SES ( $\mathrm{ft} 01, \mathrm{ft} 02, \mathrm{ft} 03, \mathrm{ft} 04$ and $\mathrm{ft} 06$ ) were conducted as part of this study. The first two tags (ft01) were deployed on a seal without any pre-deployment test. For the second deployment (ft02), 8 tags were simultaneously tested at sea at Kerguelen along a $100 \mathrm{~m}$-cast.

For the following deployment ( $\mathrm{ft} 03, \mathrm{ft} 04, \mathrm{ft} 06)$ and previous to their operational deployments on SES at Kerguelen 

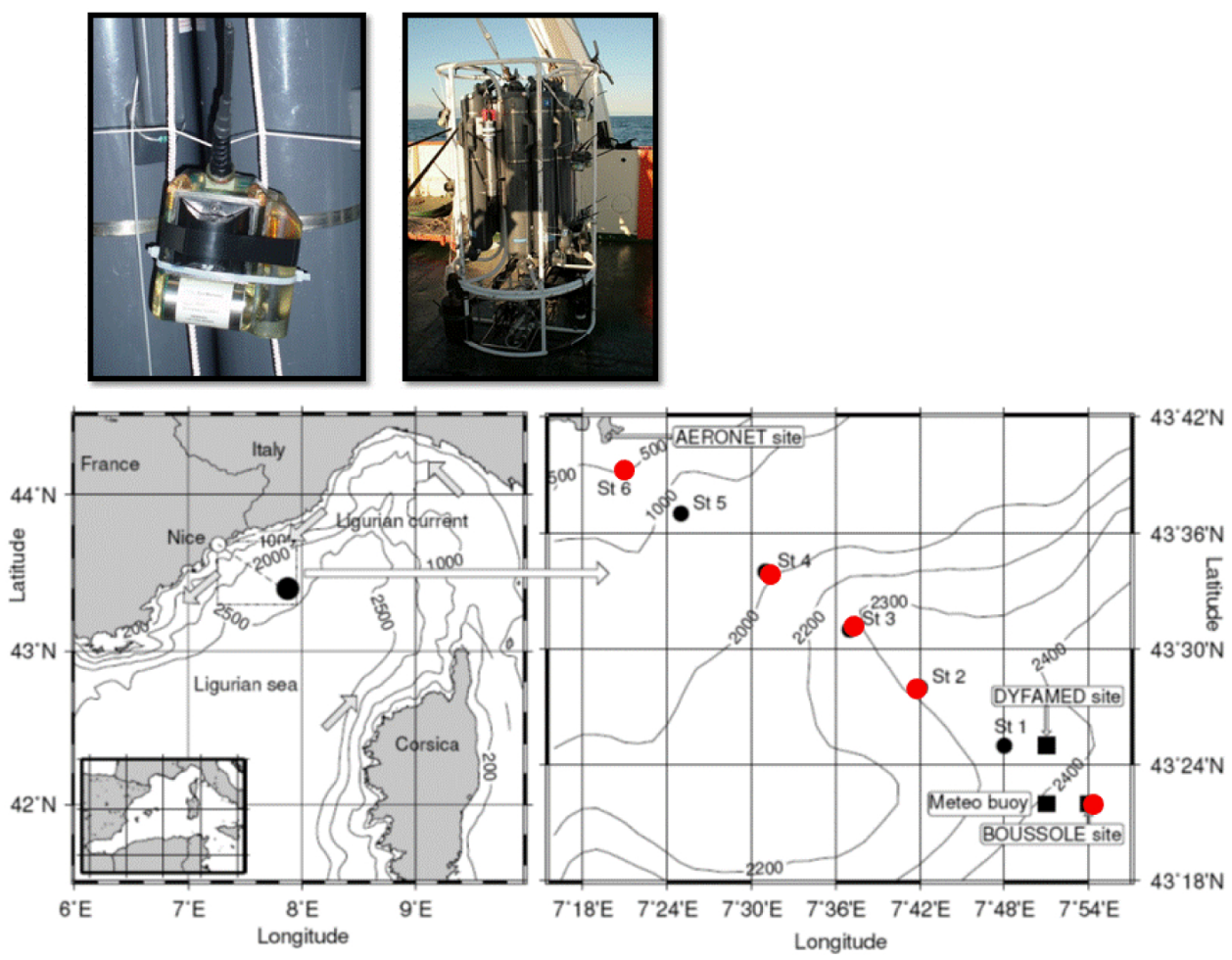

Figure 1. Top: CTD-FLUO-SRDL were fixed on the external part of the CTD-cage. Bottom: the Boussole at-sea test set up. Fluorescence profiles were conducted on stations located on the transect between Villefranche sur mer and the BOUSSOLE site (right). A fluorescence profile combined with water sampling for HLPC assessment of Chlorophyll $a$ concentration was performedat the BOUSSOLE site located 70 miles off Villefranche sur mer (left).

Island the tags were tested in the Mediterranean sea during shipboard experiments. At sea tests were performed during the BOUSSOLE oceanographic cruises on the SSV "Tethys II" (Resp. D. Antoine, LOV). Each cruise consisted of a transect between the Nice harbour and the BOUSSOLE mooring site located in the north western Mediterranean sea $\left(43^{\circ} 20^{\prime} \mathrm{N}, 7^{\circ} 54^{\prime} \mathrm{E}\right)$ with up to 6 oceanographic casts performed in between (Fig. 1). As part of the BOUSSOLE programme and associated cruises (Antoine et al., 2008) in the Ligurian Sea (Western Mediterranean), each series of tags were indeed attached to a CTD rosette generally immersed at Boussole site.

Water samples were collected for 10 different depths, filtered onboard and immediately frozen in liquid nitrogen before being stored at $-80^{\circ} \mathrm{C}$ back in the laboratory. High Performance Liquid Chromatography (HPLC) analysis of filtered samples was performed according to Ras et al. (2008) for the accurate determination of total chl $a$ and accessory pigments (other chlorophylls and carotenoids).

The in situ calibration procedures for each tag subsequently include the deep offset fluorescence correction. Offset is detected in the profile through the fluorescence value (Fluo) in deep waters (like $z>200 \mathrm{~m}$ ). Chl $a$ fluorescence is considered as null at these depths because
HPLC [chl $a$ ] is below the detection limit (DL) of the method $\left(\mathrm{DL}=0.05 \mathrm{mg} \mathrm{m}^{-3}\right)$. For each tag and each cast, the fluorescence-offset was calculated as difference between 0 and the fluorescence value provided by the fluorometer for every depth greater than $200 \mathrm{~m}$. The mean and standard deviation (SD) of the fluorescence offset was then calculated for each tag. The mean offset value calculated for a given cast and a given fluorometer was retrieved to the fluorescence values provided by this fluorometer. The at-sea test offset calculation for $\mathrm{ft} 02$ was restrained between 80 and $100 \mathrm{~m}$, for which fluorescence for all fluorometers reached constant and minimum values which were consistent with the offset values generally found during the other at-sea test.

Only the ascent values were used as (i) the water samples were only collected during the ascent phase and (ii) the CTDFluoro SRDL tags were programmed to sample the fluorescence only during the ascent phase when deployed on an elephant seal.

For this calibration procedure, tags were set on a sampling protocol and programmed to record pressure, temperature, conductivity and fluorescence every $2 \mathrm{~s}$ continuously while in the water. They were deployed to the side of the water-sampling rosette which was equipped with 11, 12 L Niskin bottles (General Oceanics) and a SBE 21 CTD 
profiler (Seabird Electronics) and with a CHELSEA AquaTrack chl $a$ fluorometer (hereafter named reference fluorometer). Chl $a$ concentration was determined by HPLC on a sample of $2.27 \mathrm{~L}$ of water collected by the Niskin bottles for one and sometime two casts during the cruise. Water samples were usually collected from 12 depths $(5,10,20,30,40,50$, $60,70,80,150,200 \mathrm{~m}$ ).

The multiple casts conducted, without water sampling, allow us to (1) assess the deep fluorescence offset for each tag and to assess its inter-cast variability and (2) to assess if discrepancies between different fluorometers were consistent among and between casts.

chl $a$ concentrations of the water samples collected on BOUSSOLE site were determined using standard fluorometric analysis of acetone extracts of the filtered samples. Water samples collected using Niskin bottles were filtered $\left(2250 \mathrm{~cm}^{3}\right.$ ) onto glass fiber filters (Whatman GF/F, nominally $0.7 \mu \mathrm{m}$ ) using positive pressure. The filters were placed in a test tube, wrapped in aluminium foil and frozen in the dark. Back in the Villefranche laboratory chl $a$ was extracted from the filter with $7 \mathrm{~mL}$ of HPLC grade acetone for $24 \mathrm{~h}$ in the dark. The pigment concentration was then analysed by the fluorometric method (Yentsch and Menzel, 1963) with a blanked and calibrated fluorometer (Turner Designs 10-AU).

Despite the off-set correction and a good agreement in the general shape of the fluorescence profiles provided by each fluorometer for a given cast, differences in absolute fluorescence values are clearly noticeable between fluorometers (see Fig. 2) which means that the calibration parameters provided by the manufacturer were not precise enough and/or that the integration of the fluorometer into the CTD SRDL tag degraded the fluorometer calibration. Therefore, the fluorometers of the CTD-Fluo tags needed to be re-calibrated in situ again.

To do so, for a given cast, the regression coefficient was calculated (without constant) for depth ranging between 0 and $200 \mathrm{~m}$ between the offset corrected fluorescence values provided by each CTD-Fluo SRDL and the reference fluorometer. This was performed for $\mathrm{ft} 03 / \mathrm{ft} 04$ and $\mathrm{ft} 06$ deployments. Several casts were conducted for a given at-sea test allowing to estimate intra and inter-fluorometer variability.

\section{Post-deployment procedure}

The second step was to proceed to the inter-calibration of the fluorometers between all the at-sea tests and this was essential for the $\mathrm{ft} 01$ and $\mathrm{ft} 02$ for which no proper complete at-sea calibration procedure was performed previous to seal deployment. For $\mathrm{ft} 02$, the simultaneous testing of all the tags provided information about the proportionality between the fluorescence measurements provided by the different fluorometers and that information was used.

To intercalibrate the tags between each deployment we used all the information provided by at-sea tests as well as the proportionality found between surface values provided by the tag fluorometer within a deployment and the corresponding chl $a$ surface values provided by MODIS. IMODIS values were not used as an absolute measurement of [chl $a$ ], but as a relative measurement to better assess the proportionality between each fluorometer. An 8-day composite $9 \mathrm{~km}$ scale resolution MODIS data was the highest usable resolution to investigate the relationship between in situ surface fluorescence chl $a$ and those provided by MODIS. Indeed too few MODIS values were available to investigate this relationship at a higher temporal (daily) and spatial $(1 \mathrm{~km})$ resolution at the tag level. The tag's surface fluorescence values used were offset and quenching corrected and saturated values retrieved (see below). The relationships found between the MODIS surface fluorescence values for each deployment was used to proceed to the production of a homogeneous fluorescence dataset.

\section{Conversion to chl $a$ concentration}

The inter-calibrated fluorescence values were then converted into a chl $a$ concentration value by using the relationship between the chl $a$ concentration provided by the reference fluorometer and the $[\mathrm{chl} a]$ provided from HPLC measurements. This relationship was estimated over 70 test profiles ranging between 0 to $200 \mathrm{~m}$ and performed between 2002 and 2009 . As all these profiles were performed during daylight hours, therefore, only fluorescence values deeper than $30 \mathrm{~m}$ were used to avoid any quenching effect and fluorescence values provided by the reference fluorometer were offset corrected.

\subsubsection{Deployment on elephant seals}

Instruments were deployed on SES either at the end of their moult in late summer to cover their pre-breeding, winter foraging trips or in October on post-breeding females. Animals were anesthetised with intravenous injection of tiletamine and zolazepam $1: 1$, and then instruments were attached to the fur on their head by using a two component industrial epoxy. Seals dove repeatedly with CTD-Fluo data being collected every $2 \mathrm{~s}$ during the ascent phase of dive and processed onboard before being transmitted via the Argos satellite system when animals were at the surface. On average, $1.8 \pm 0.5$ vertical temperature $(T)$, conductivity $(C)$ and fluorescence profiles were transmitted daily. Because of the narrow bandwidth of Argos transmitters, each profile was transmitted in a compressed form consisting of 18 fluorescence and $24 T$ and $C$ data points. The 18 first $T$ and $C$ corresponded to the fluorescence measurements for the $0-180 \mathrm{~m}$ depth range. Fluorescence, $T$ and $C$ measurements were averaged over $10 \mathrm{~m}$ bin sampled for the upper $180 \mathrm{~m}$ of the dive. The 6 additional $T$ and $C$ corresponded to the most important inflection points determined onboard over between $180 \mathrm{~m}$ and the deepest part of the dive by using a "broken stick algorithm" (Roquet et al., 2011). 

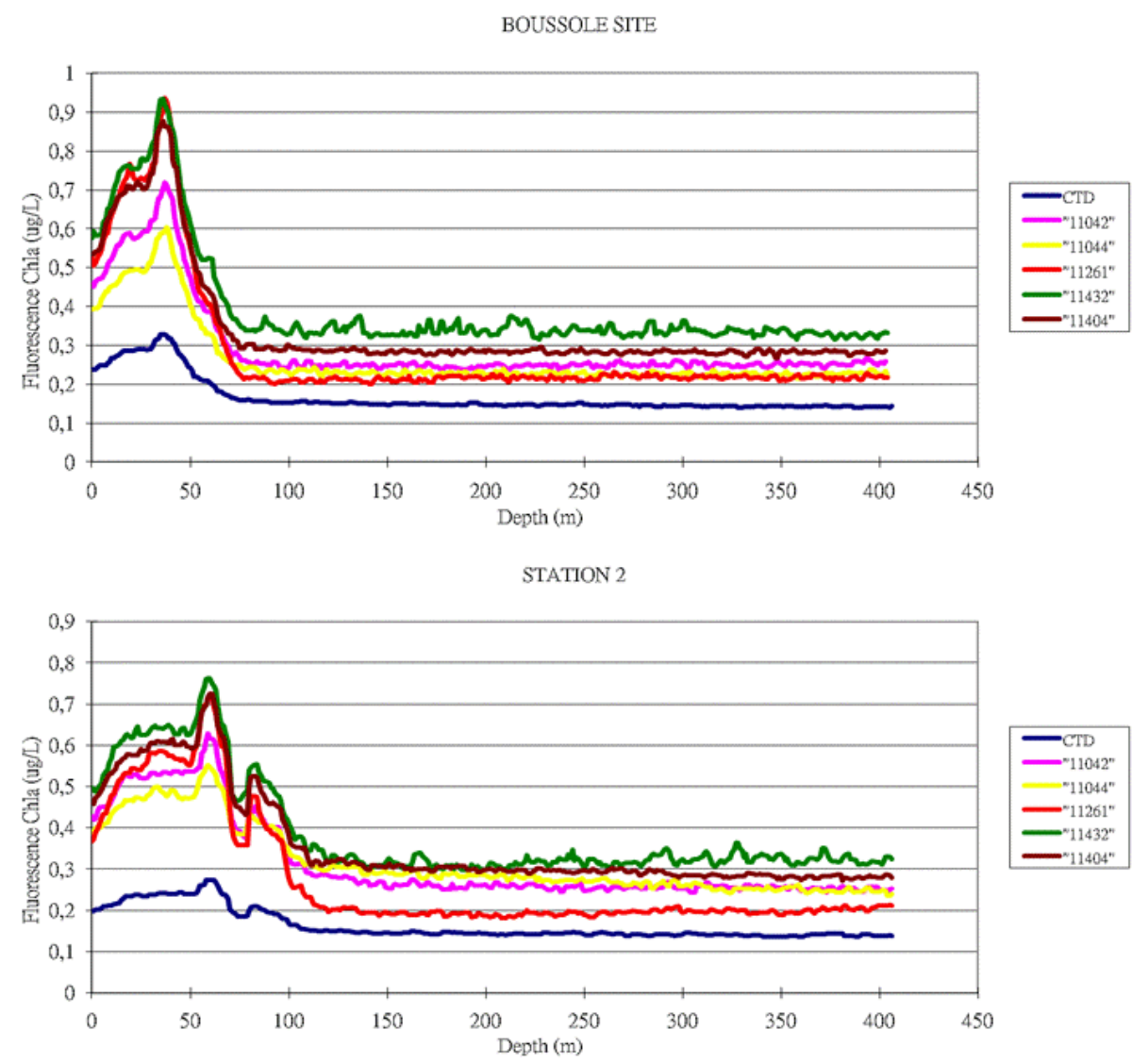

Figure 2. Example of fluorescence profiles provided by different CTD-FLUO-SRDLs and the reference fluorometer (in blue) obtained at two different stations. These profiles exhibit the existence of a fluorescence offset differing between CTD-FLUO-SRDLs. Fluorometers were providing consistent data between each other, but differed in the absolute amount of fluorescence produced.

\subsubsection{Post deployment issues and correction processes}

\section{Chl $a$ saturated values}

According to chl $a$ measurements available for the study area $\mathrm{ft} 02$, ft03, ft04 CTD-Fluoro SRDL Tags the Cyclops 7 fluorometer gain was set to monitor chl $a$ concentration ranging between 0 and $2.5 \mu \mathrm{g} \mathrm{L}^{-1}$. In situation of high in situ chl $a$ concentration, some raw profiles exhibited saturated values. Therefore, these profiles were flagged accordingly and retained as saturated one in the data base. For the ft06 Tags the gain of the Cyclops 7 fluorometer was set for a dynamical range of 0 to $4 \mu \mathrm{g} \mathrm{L}^{-1}$ and saturated chl $a$ profiles were exceptionally encountered and flagged accordingly. Unsaturated profiles were flagged as "1" while saturated profiles were flagged as " 2 ".

\section{Offset correction}

Initially each in situ profiles was corrected according to the mean offset calculated for each tag from the at-sea test conducted prior to deployments which exhibited very little variability for a given fluorometer between cast (see result part).
However, post deployment values revealed that this offset could vary over time and the reasons for such variations are not yet fully understood, but are thought to be related to the water masses encountered and in particular the amount of non-phytoplanktonic particles. The use of a constant offset correction was leading to positively or negatively bias profiles values depending on situations. Therefore, a profile-byprofile-offset-correction method was implemented and three cases were distinguished and flagged accordingly. In the first situation the 4 deepest chl $a$ values corresponded (i) to the minimum values of the profiles, with a standard deviation (SD) on chl $a$ value lower than $10 \%$. In this situation the lowest chl $a$ value among the 4 deepest values was used as the offset value and the whole profile was corrected and flagged as " 1 "; (ii) when the deepest chl $a$ values did not correspond to the minimum values, or when the SD was higher than $10 \%$ the profile was flagged as " 2 " and was corrected according to the mean offset calculated for that Tag over the whole deployment period; (iii) a third situation was observed in a few cases, and for which chl $a$ concentration was increasing at depth. No offset correction was applied to these profiles 
which were flagged as " 3 " and these flag 3 profiles are not integrated in the current data base.

\section{Quenching correction}

In both, laboratory and field studies, a daily rhythm of in vivo fluorescence that is not correlated with diel changes in the concentration of chl $a$ have been reported in a number of studies. During periods of high irradiance, fluorescence tends to be lower than the value at night (Kiefer, 1973; Loftus and Seliger, 1975; Falkowski and Kolber, 1995; Dandonneau and Neveux, 1997; Behrenfeld and Kolber, 1999; Kinkade et al., 1999). The photo-inhibition of phytoplankton by an excess of light, result in a decrease of the fluorescence quantum yield (i.e., the ratio of photons emitted as fluorescence to those absorbed by photosynthetic pigments). This is often ascribed to a set of processes generally termed nonphotochemical fluorescence quenching (NPQ; Falkowski and Kolber, 1995; Krause and Jahns, 2004). Quenching is commonly observed during daytime with a maximum intensity at midday (Kiefer, 1973; Dandonneau and Neveux, 1997) and it is referred as daytime fluorescence quenching. Quenching poses a problem and, therefore, need to be accounted for. We applied the new method of quenching correction developed, tested and successfully applied to fluorescence data collected by elephant seals (Xing et al., 2012). In short, for mixed type waters, the maximum fluorescence values within the mixed layer is extended to the surface (i.e., all upper points are replaced by this maximum value). However, for stratified waters, which usually have a thin mixed layer, obviously, the quenching effect will pass through the mixed layer into the stratified layer. In the stratified layer, we were unable to perform such correction and only night time fluorescence profiles were used. However, the stratified layer situations were only encountered for $16 \%$ of the fluorescence profiles sampled, and nearly half of them were obtained at night. In this process, we assume the maximum value in the mixed layer as the non-quenching value and all above points are corrected to the same value (see Xing et al., 2012). After implementing such corrections, no differences could be detected between day time fluorescence corrected profiles and the proximate night profiles (just before or after the day profiles).

\subsubsection{Estimation of the tag specific chl $a$ correction coefficient: a Bayesian approach}

Using a Bayesian adjustment framework and by combining each at-sea test, the information available for each profile and the HPLC values available, a chl $a$ calibration coefficient was calculated for each CTD-Fluoro SRDL tag. A Bayesian framework is especially suited as it guarantees that between-casts variability is taken into account in estimating these inter-fluorometer coefficients. An attractive feature of this framework is the relative ease with which different datasets are combined in a single analysis, allowing infor- mation transfer between disparate sources. Another advantage stems from the easy computation of confidence intervals for parameters of interest and prediction errors. Models were fitted with WinBUGS (Spiegelhalter et al., 2003) called from $R$ (R Development Core Team, 2009) with the package R2WinBUGS (Sturtz et al., 2005). Weakly informative and robust priors were favoured. We used uniform priors (Gelman, 2006) for standard deviation parameters. Because all slopes were expected to be positive, we used Student-t priors with mean 0 , scale 10 and $7 \mathrm{df}$ on a log scale (Gelman et al., 2008). Batches of tag-specific coefficient were assumed to follow a bivariate Gaussian distribution with covariance matrix $\sum$. We used the prior described in Tokuda et al. (2011) for the covariance matrix $\sum$.

We built a model to predict HPLC [chl $a$ ] from either in situ fluorescence (Fluo) measured by instrumented SES or from MODIS chl. Specifically we first used long-term data at the Boussole site to estimate the relationship between HPLC [chl $a]$ and measurement from the reference fluorometer:

$\operatorname{HPLC}[\mathrm{chl} a]=\delta \cdot$ Fluo[reference $]+\varepsilon 1$

where $\varepsilon 1$ is a Gaussian residual error term.

Secondly, we used data from the intercalibration experiment to estimate the relationship between a specific tag $j$ and the reference fluorometer:

Fluo $[$ reference $]=\alpha j \cdot($ Fluo $j-$ Offset $j)+\varepsilon 2$

where $\varepsilon 2$ is a Gaussian residual error term. When measurements from the reference fluorometer were unavailable, but measurements from the different tags at a specific location were available, we rewrote Eq. (3) as:

Fluo[reference $]-(\alpha j \cdot($ Fluo $j-$ Offset $j)+\varepsilon 2)=0$

and put a weakly informative prior (Half-Student-t with mean 0 , scale 5 and $4 \mathrm{df}$, Gelman et al., 2008) on the value of Fluo [reference]. We then used the WinBUGS "zero-trick" (Spiegelhalter et al., 2003) to incorporate these data into the model. Note that the error term $\varepsilon 2$ is the same for Eqs. (3) and (4).

Finally, we evaluated the relationship between in situ fluorescence as measured from a specific tag $j$ and MODIS:

$($ Fluo $j-$ Offset $j)=\beta j \cdot$ MODIS $+\varepsilon 3$

where $\varepsilon 3$ is a Student residual error term. Equation (5) is a regression with heteroskedastic noise to account for possible outliers, or extreme observations, when evaluating the relationship between MODIS and in situ fluorescence. To make robust inferences, the parameter $v$, that is the degrees of freedom of the Student distribution, was estimated from the data (with a Gamma (shape $=2$, scale $=4$ ) prior for $v$ ). All data points available and corresponding to a match between chl $a$ provided by MODIS and the fluorometer for a given tag were used in estimating $\beta j$. 
Table 1. Details of the 23 CTD-fluo tags deployments. Deployment date, Sampling period, number of fluoro-profiles obtained, and correction coefficient applied to each tag.

\begin{tabular}{|c|c|c|c|c|c|c|c|c|c|c|c|c|}
\hline $\begin{array}{l}\text { Deployment } \\
\text { number }\end{array}$ & $\begin{array}{l}\text { CTD- } \\
\text { Fluo } \\
\text { SRDL } \\
\text { number }\end{array}$ & $\begin{array}{l}\text { Deployment } \\
\text { date }\end{array}$ & $\begin{array}{l}\text { End trans- } \\
\text { mission }\end{array}$ & $\begin{array}{l}\text { number of } \\
\text { fluorescence } \\
\text { profiles } \\
\text { collected }\end{array}$ & $\begin{array}{l}\text { number of } \\
\text { fluorescence } \\
\text { profiles } \\
\text { usable }\end{array}$ & $\begin{array}{l}\text { Daylight } \\
\text { hours } \\
\text { profile }\end{array}$ & $\begin{array}{l}\text { night } \\
\text { hours } \\
\text { profile }\end{array}$ & $\begin{array}{l}\text { nb of } \\
\text { saturated } \\
\text { profile }\end{array}$ & $\begin{array}{l}\text { nb of } \\
\text { quenching } \\
\text { corrected } \\
\text { profile }\end{array}$ & $\begin{array}{l}\text { nb prof } \\
\text { flag } 1 \\
\text { offset } \\
\text { profile }\end{array}$ & $\begin{array}{l}\text { nb of prof } \\
\text { flag } 2 \\
\text { Offset } \\
\text { profile }\end{array}$ & $\begin{array}{l}\text { Mean offset } \\
\text { (predeploy- } \\
\text { ment sea } \\
\text { test) }\end{array}$ \\
\hline FT01 & 10863 & $12 / 22 / 2007$ & $6 / 5 / 2008$ & 241 & 241 & 166 & 75 & 32 & 76 & 212 & 29 & - \\
\hline FT02 & 10946 & $1 / 20 / 2009$ & $12 / 20 / 2009$ & 331 & 331 & 187 & 144 & 1 & 145 & 248 & 83 & 1.28 \\
\hline FT02 & 11034 & $1 / 20 / 2009$ & $3 / 12 / 2009$ & 73 & 73 & 45 & 28 & 0 & 15 & 40 & 33 & 0.36 \\
\hline FT02 & 11035 & $1 / 28 / 2009$ & $9 / 21 / 2009$ & 404 & 404 & 202 & 202 & 0 & 148 & 292 & 112 & 0.44 \\
\hline FT02 & 11039 & $1 / 25 / 2009$ & $7 / 13 / 2009$ & 289 & 289 & 169 & 120 & 51 & 122 & 215 & 74 & 0.72 \\
\hline FT02 & 11040 & $1 / 20 / 2009$ & $2 / 16 / 2009$ & 41 & 41 & 26 & 15 & 1 & 13 & 30 & 11 & 0.43 \\
\hline FT02 & 11042 & $12 / 24 / 2008$ & $6 / 1 / 2009$ & 236 & 229 & 118 & 111 & 33 & 113 & 146 & 83 & 0.71 \\
\hline FT02 & 11044 & $1 / 10 / 2009$ & $6 / 19 / 2009$ & 267 & 267 & 139 & 128 & 92 & 66 & 238 & 29 & 0.51 \\
\hline FT03 & 11038 & $10 / 17 / 2009$ & $12 / 31 / 2009$ & 141 & 130 & 82 & 48 & 63 & 50 & 71 & 59 & 0.20 \\
\hline FT03 & 11259 & $10 / 19 / 2009$ & $1 / 4 / 2010$ & 134 & 125 & 72 & 53 & 35 & 50 & 85 & 40 & 0.17 \\
\hline FT03 & 11260 & $10 / 20 / 2009$ & $1 / 9 / 2010$ & 156 & 155 & 101 & 54 & 42 & 82 & 122 & 33 & 0.23 \\
\hline FT03 & 11262 & $10 / 23 / 2009$ & $1 / 18 / 2010$ & 169 & 169 & 114 & 55 & 45 & 100 & 144 & 25 & 0.28 \\
\hline FT03 & 11263 & $10 / 21 / 2009$ & $1 / 9 / 2010$ & 157 & 156 & 114 & 42 & 12 & 91 & 116 & 40 & 0.16 \\
\hline FT04 & 11042 & $3 / 8 / 2010$ & $5 / 25 / 2010$ & 97 & 51 & 0 & 51 & 0 & 0 & 38 & 13 & 0.24 \\
\hline FT04 & 11044 & $2 / 20 / 2010$ & $8 / 19 / 2010$ & 314 & 128 & 0 & 128 & 2 & 0 & 95 & 33 & 0.23 \\
\hline FT04 & 11261 & $2 / 15 / 2010$ & $2 / 27 / 2010$ & 13 & 6 & 0 & 6 & 1 & 0 & 4 & 2 & 0.21 \\
\hline FT04 & 11404 & $2 / 20 / 2010$ & $9 / 25 / 2010$ & 418 & 125 & 1 & 124 & 1 & 0 & 82 & 43 & 0.28 \\
\hline FT04 & 11432 & $3 / 12 / 2010$ & $9 / 15 / 2010$ & 309 & 112 & 0 & 112 & 0 & 0 & 87 & 25 & 0.33 \\
\hline FT06 & 10946 & $11 / 4 / 2010$ & $1 / 19 / 2011$ & 150 & 101 & 61 & 40 & 7 & 44 & 101 & 0 & \\
\hline FT06 & 11035 & $11 / 4 / 2010$ & $1 / 9 / 2011$ & 120 & 102 & 84 & 18 & 35 & 53 & 102 & 0 & 0.30 \\
\hline FT06 & 11038 & $11 / 2 / 2010$ & $1 / 25 / 2011$ & 162 & 88 & 66 & 22 & 70 & 48 & 88 & 0 & \\
\hline FT06 & 11262 & $10 / 22 / 2010$ & $12 / 30 / 2010$ & 136 & 6 & 3 & 3 & 0 & 2 & 6 & 0 & 0.24 \\
\hline FT06 & 11263 & 9/9/2010 & $11 / 24 / 2010$ & 140 & 59 & 26 & 33 & 1 & 26 & 59 & 0 & 0.16 \\
\hline Total & & & & 4498 & 3388 & 1776 & 1612 & 524 & 1244 & 2621 & 767 & \\
\hline
\end{tabular}

Combining Eqs. (2) and (3) yields:

HPLC $[\operatorname{chl} a]=\delta \cdot$ Fluo[reference $]=\delta \cdot \alpha j$

$$
\text { .(Fluo } j-\text { Offset } j \text { ) }
$$

where $\delta \cdot \alpha j$ is a tag specific calibration coefficient allowing to predict HPLC [chl $a$ ] from in situ fluorescence. Combining Eqs. (5) and (6) further yields:

HPLC $[\operatorname{chl} a]=\delta \cdot \alpha j \cdot \beta j$ MODIS

which allows us to predict for each tag the likely value of HPLC [chl $a$ ] from MODIS measurement.

\section{Results}

\subsection{At-sea trials prior to deployment}

The at-sea testing previous to deployment revealed two types of issues which were tag's fluorometer dependant: (1) a fluorescence offset was, therefore, an instrument-specific clean water background, equivalent to the lowest values observed in the deepest part of the fluorescence profiles was subtracted from the raw fluorescence values; (2) for offset-corrected fluorescence profiles, differences between tags in the absolute amount of fluorescence were detected.

The variability of the fluorescence offset for a given tag was one order of magnitude smaller than the offset differences between tags (Table 1). The mean fluorescent offset for the tested tags during the BOUSSOLE cruise was
$0.24 \pm 0.05 \mu \mathrm{g} \mathrm{L}^{-1}$ (range $0.16-0.33, n=14$ ). For a given tag, the standard deviation of inter-cast fluorescent offset ranged from $\left(0.0007\right.$ to 0.0620 , mean $\left.=0.0148 \mu \mathrm{g} \mathrm{L}^{-1}\right)$.

\subsubsection{Tag's fluorometer intercalibration}

The multiple cast performed during the at-sea test prior to $\mathrm{ft} 03$, ft04 and ft06 deployments allowed assessing the intra tag-fluorometer variability. This variability ranged from to a minimum of $0.03 \%$ to a maximum of $5.61 \%$ with a mean of $2.08 \pm 1.84 \%$. However, the difference between fluorometers was one order of magnitude larger than the within fluorometer variability and one fluoromenter provided fluorescence values which were on average 2.61 time higher than the minimal values. The mean inter-fluorometer variation in fluorescence values was $69 \%$ (range 0.005 to $261 \%$ ).

On average $\alpha j$ indicated that the tested fluorometers provided [chl $a$ ] 4 times greater (i.e., $0.24^{-1}$ ) than the reference fluorometer.

\subsubsection{Reference fluorometer-HPLC relationship}

Over the 2002-2009 period, HPLC values were found to be linearly related to the chl $a$ estimates provided by the reference fluoremeter. $\delta$ was estimated to be 2.53 (i.e., chl $a$ concentration provided by HPLC were found to be 2.53 higher than those estimated from the reference fluorometer (Fig. 3, Table 1). The tag fluorometers provided chl $a$ concentration 
which were on average 1.64 time greater than chl $a$ concentration provided by concomitant HPLC measurements.

\subsection{Post deployment data}

From December 2007 to July 2010, a total of 27 SES, were fitted tags, of which 23 provided usable fluorescence data (Table 1). The 23 SES tracks provided a broad geographic and seasonal coverage ranging from Antarctic to subtropical waters, but with most individuals concentrating east of Kerguelen Island within the Kerguelen plume (Fig. 4). A total of 4662 fluorescence profiles were transmitted, but 1274 of them either incomplete, with constant values or presenting obvious anomalies were discarded (i.e., $27 \%$ ). Among the remaining 3388 profiles 1776 were collected during the day and 1612 at night and year round (Fig. 5). The summary of the different profiles and flagging situation are provided in Table 1. This dataset (doi:10.7491/MEMO.1) is freely available at http://www.cebc.cnrs.fr/ecomm/Fr_ecomm/ecomm memoOCfd.html.

524 profiles exhibited saturated fluorescence values (i.e., $18 \%$ ) and were excluded for the comparison with the corresponding weekly chl $a$ MODIS data. However, due to heavy cloud cover only 884 surface values of CTD-fluo profiles (i.e., $30.9 \%$ ) could be matched with the weekly MODIS data, and 126 with the MODIS data collected on the same day (i.e., $4.4 \%)$.

Among these 23 tags deployed on SES, 8 were recovered when SES came back onshore after at sea periods ranging between 3 to 8 months. At recovery the optical face of Cyclops 7 was clean with no bio-fouling most likely because elephant seals are typically deep divers spending very short periods within the euphotic zone. Furthermore, they spent most time at low temperatures.

On the 3388 fluorescence profiles, $40 \%$ exhibited day time fluorescence quenching (i.e., $70 \%$ of daytime profiles - Table 1). Therefore these profiles were corrected according to the procedure proposed by Xing et al. (2012). The recovery of fluorescence from quenching is obvious when we compare day profiles with night profiles obtained for the same location at the same date (Fig. 6). Individual seal collected chl $a$ transects along their track monitoring latitudinal/longitudinal changes for a given time period as well as seasonal change within a given area (Fig. 7).

As quenching could only be corrected in well mixed water and not in stratified ones, we were (1) unable to proceed to quenching correction of fluorescence profiles in 283 profiles (i.e., about $16 \%$ of daytime profiles) and therefore unable to assess properly deep maximum fluorescence for these daytime fluorescence profiles. To address this question we only used the 1612 night time profiles. Among those 352 had a maximum value at surface, while 742 exhibited a maximum deeper than $30 \mathrm{~m}$. However, the vast majority the maxima was not exceeding the surface values by more than $30 \%$ (i.e., 1423 profiles). Only 148 night profiles (i.e., $9 \%$ of the to-

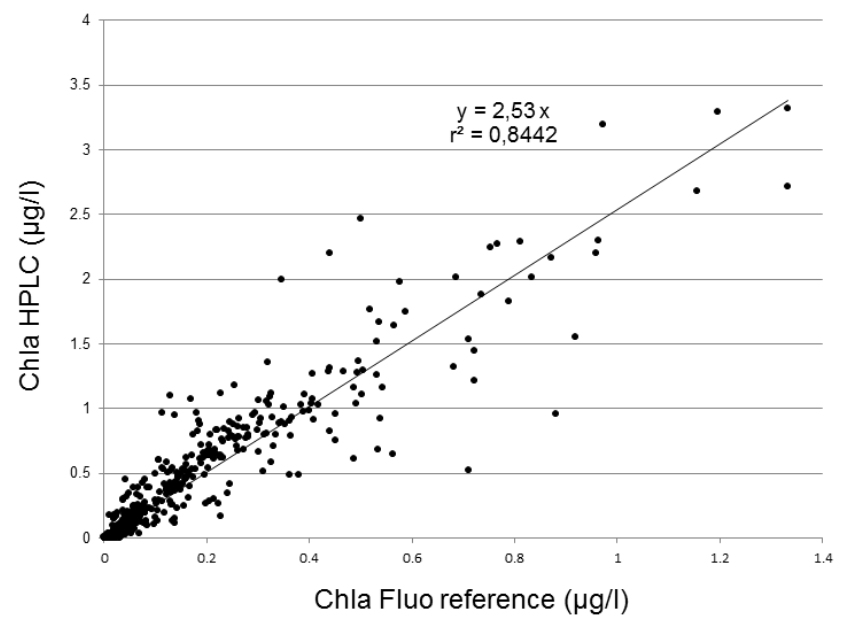

Figure 3. Relationship between the chl $a$ concentration provided by the reference fluorometer and the chl $a$ concentration estimated from HPLC measurements. This relationship was estimated over 70 test profiles ranging between 30 to $200 \mathrm{~m}$ and performed between 2002 and 2009.

tal number of night profiles) had a deep maximum exceeding $30 \%$ of the surface value (maximum: $180 \%$ ). The depth class distribution of the maxima values exceeding $30 \%$ of the surface value are shown in Fig. 8 and exhibit a clear bimodal distribution with a $30-40 \mathrm{~m}$ and a $70-80 \mathrm{~m}$ modes.

No obvious spatial structuring in the distribution of these profiles could be identified through the range of the SES.

Deep offset and quenching corrected surface fluorescence values provided by intercalibrated tags according to the reference fluorometer ( $\mathrm{ft} 03, \mathrm{ft} 04$ and $\mathrm{ft} 06$ ) were related to the corresponding MODIS chl $a$ value along SES tracks. This relationship was implemented within the Bayesian framework to correct tag fluorescence values for which no at-sea test was performed previous to the deployment. For the $\mathrm{ft} 02 \mathrm{de}-$ ployment the proportionality found between tags, all tested simultaneously at sea was used. Following the Bayesian procedure previously described the correction coefficients $(\delta \cdot \alpha j$, mean value) applied to each tag were calculated and are given in Table 2.

The surface [chl $a$ ] values derivated from by offset and quenching corrected profiles were found to be related to the 8-day-9 km MODIS chl $a$ values. On average MODIS values were 3.04 times $(\beta j$, range: $1.90-8.74)$ lower than the corresponding tag fluorometer, and we found that on average, MODIS tended to underestimate HPLC related [chl $a$ ] by a mean $1.99(\delta \cdot \alpha j \cdot \beta j$, range: $1.04-3.21)$ factor compared to the in situ estimates provided by the inter-calibrated fluorescence tag (Table 2, Fig. 9). The variability of $\beta j$ (i.e., the Fluoremeter/MODIS relationship) was on average larger than the inter-fluorometer one, suggesting that a large part of the error is likely due to the poor relationship found between $[\mathrm{chl} a$ ] provided by individual fluorometers and MODIS. However, this work emphasises that despite the fact that all 


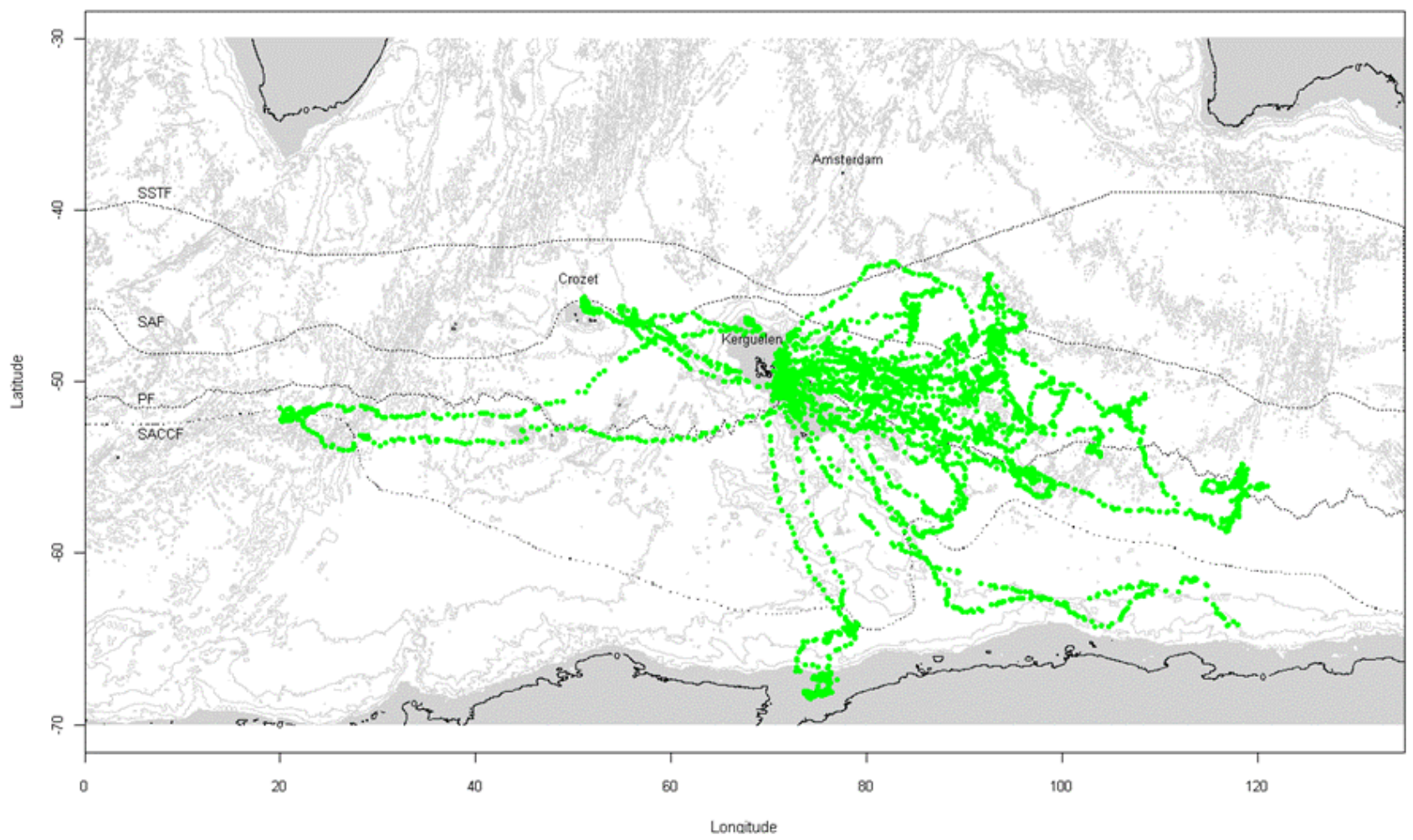

Figure 4. Location of the fluorescence profiles along the tracks of 24 SES successfully equipped with a CTD-FLUO-SRDL and collected within the scope of this study (December 2007-January 2011).

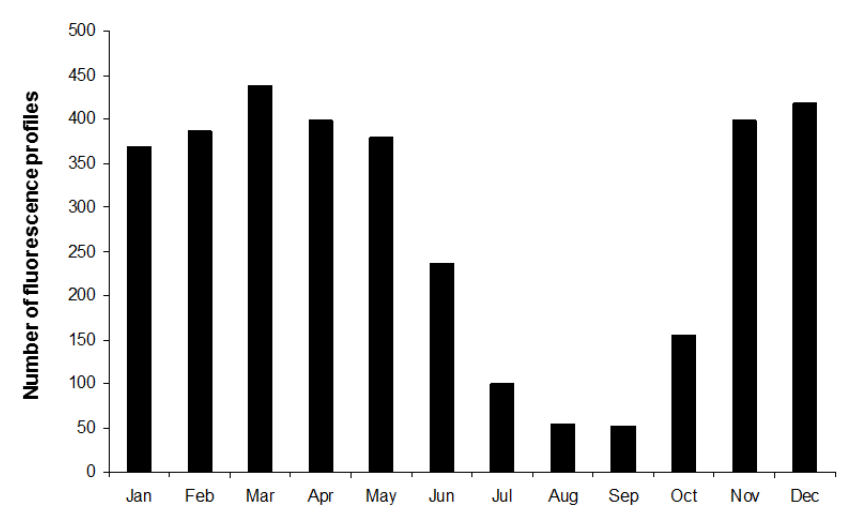

Figure 5. Monthly distribution of the fluorescence profiles.

the fluorometers were identical, nevertheless some large differences could be observed between fluorometers with $\alpha j$ ranging between 0.11 and 0.36 (mean: 0.24) and those differences in themselves require those fluorometers to be intercorrected between each other. For the SO total absence of chl $a$ was never detected by MODIS with the lowest value observed of $0.06 \mu \mathrm{g} \mathrm{L}^{-1}$ in our case, while in situ fluorescence measurements suggest that total absence $( \pm 0.025 \mu \mathrm{g} \mathrm{L}-1$, i.e., the detection limit of the Cyclops 7 fluorometer) of chl $a$ can be observed.

\section{Discussion and conclusion}

The fluorescence profiles collected by the SES within the SO, provides 3-D information on otherwise poorly sampled area such as the Antarctic sea-ice zone, an area were the ocean satellites are blinded by sea-ice and/or cloud cover. SES provided an unequalled dataset of fluorescence profiles associated with temperature and salinity measurements (i.e., density) for a broad sector of the Indian part of the SO and this dataset represents a significant contribution in to understanding of the seasonal variation of phytoplankton biomass.

The significant contribution of this study was to propose a detailed and step-by-step procedure to intercalibrate the fluorometer to provide consistent chl $a$ estimates. To summarise the first step requires the correction of the deep fluorescence offset, the second step requires to have at least a common reference fluorometer between the performed tests. The third step, i.e., to proceed to the HPLC calibration, requires eliminating quenching affected fluorescence surface values obtained during daytime or better to perform night fluorescence profiles. Furthermore, we suggest that this HPLC intercalibration should not to be performed on a profile-toprofile basis, but instead according to the fluorescence/chl $a$ relationship established from multiple at-sea tests. We found, in this study, that while the fluorescence-HPLC chl $a$ relationship can vary from one at-sea test to the other, however, 

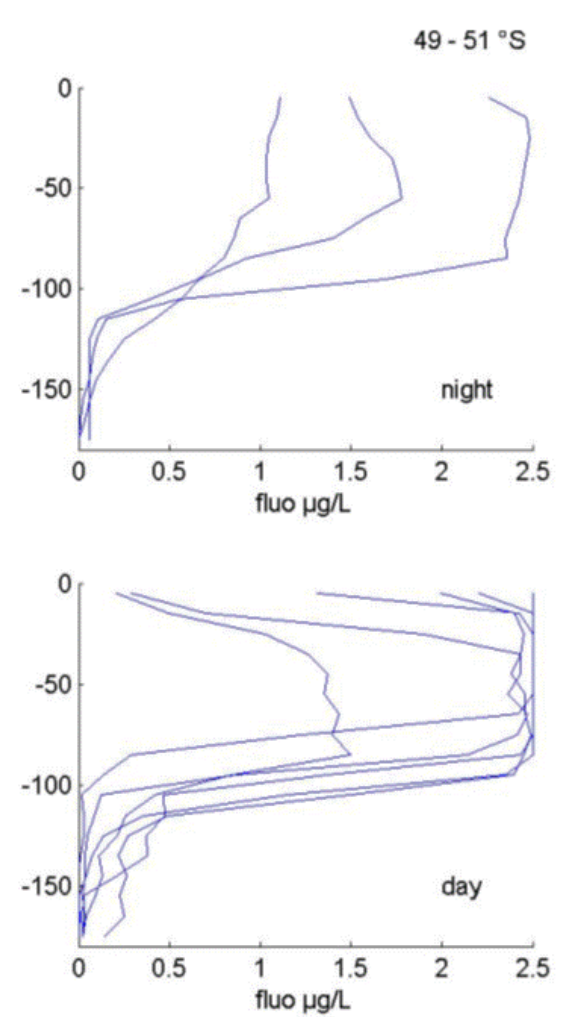

Figure 6. Example of unquenched night fluorescence profiles (top) and quenched day ones (bottom) collected on the same location and same period by a CTD-FLUO-SRDL deployed on a male SES foraging over the Kerguelen plateau.

the long-term relationship established over several years and encompassing numerous at-sea test exhibit a very good linear relationship (Fig. 3). Therefore, we suggest using this global relationship to transform the inter-calibrated fluorescence values provided by the fluorometers to an actual estimation of $[\mathrm{chl} a]$ value. In a last step when there are sufficient surface fluorescence measurements coinciding with MODIS one, MODIS data can be used as a common but weak relative (not absolute) reference between fluorometers as many issues are affecting the quality of the relationship: low number of corresponding values, a poor temporal and spatial correspondence when using $9 \mathrm{~km}$ weekly data.

Due to logistical constraints, all the inter-calibrations were performed form at-sea test conducted in the north-west Mediterranean Sea. This could result in some differences in the absolute amount of chl $a$ estimated from fluorescence data in the SO and this point should be investigated in greater details in future studies. This procedure, nevertheless, presents the major advantage of producing a dataset in which all fluorometers are inter-calibrated with each other. Furthermore the long-term relationship established between the reference fluorometer and HPLC in the north-west Mediterranean Sea is likely to be robust as it was established over

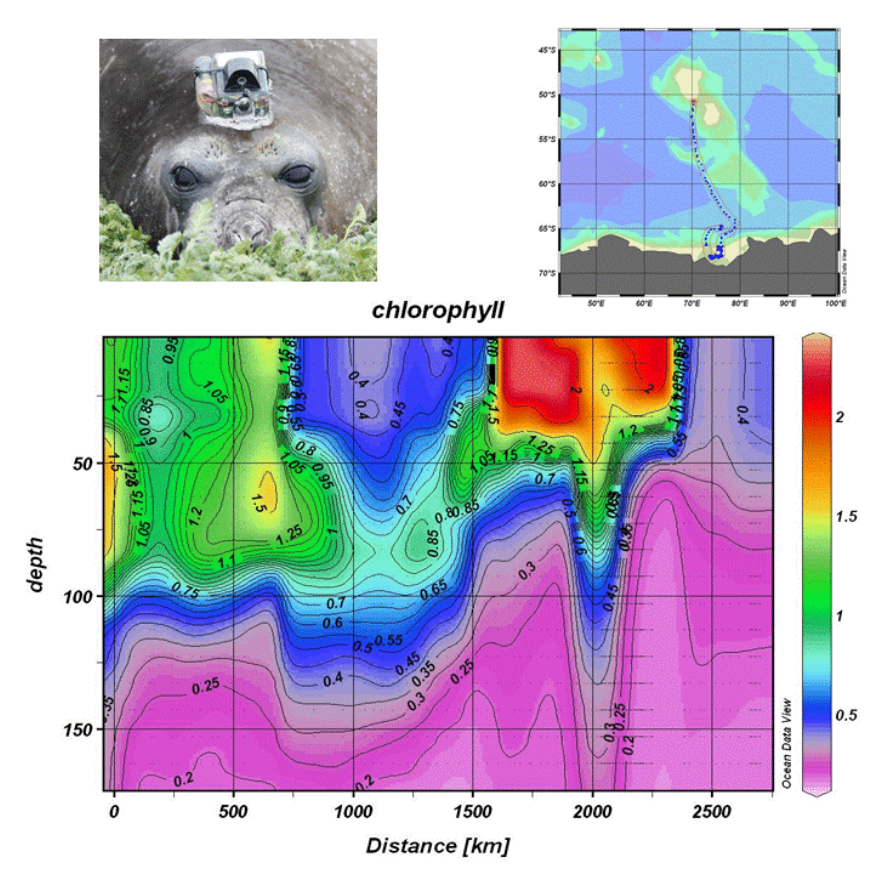

Figure 7. Top: female SES equipped with a CTD-FLUO-SRDL and section to the track followed by a juvenile SES female between January-April 2009. This female left Kerguelen on 12 January and reached the Antarctic shelf on 6 February. This female left the Antarctic shelf on 14 March, the female then remained associated with the marginal ice zone and the Antarctic divergence. Bottom: interpolated quenching corrected fluorescence profiles provided by this SES along its track. This tag exhibited a fluorescence offset of $0.2 \mu \mathrm{g} \mathrm{L}^{-1}$ of chl $a$ and Antarctic values higher than $2 \mu \mathrm{g} \mathrm{L}^{-1}$ were saturated. The abrupt change in chl $a$ concentration ( $k m$ 2400) coincides with sea-ice formation which took place in mid march. These data show both the latitudinal change in the phytoplankton concentration along a north south transect performed during the inward trip (i.e., $1600 \mathrm{~km}$ south of Kerguelen $500 \mathrm{~m}$ isobath) and the transition in phytoplankton concentration in Antarctic waters from summer to fall (from km 1600 to 2400).

a broad range of years and seasons encompassing different phytoplankton assemblages.

One important result of this study was to show that MODIS may underestimate surface [chl $a$ ] compared to in situ measurements provided by the inter-calibrated fluorometers (Fig. 9). In situ chl $a$ concentration provided by the fluorometer was correlated with the MODIS, but data points were highly dispersed. This is not surprising due to the low spatial and temporal resolution of the MODIS data used to investigate this relationship while surface values collected by the tags were associated with a unique location within that $9 \times 9 \mathrm{~km}$ sector and, therefore, small scale variation which can be measured by the fluorometer are likely to be overlooked by the $9 \times 9 \mathrm{~km}$ MODIS and weekly data.

This finding is consistent with several studies showing that standard satellite ocean colour algorithms tend to underestimate chl $a$ concentrations in the SO compared to in situ 


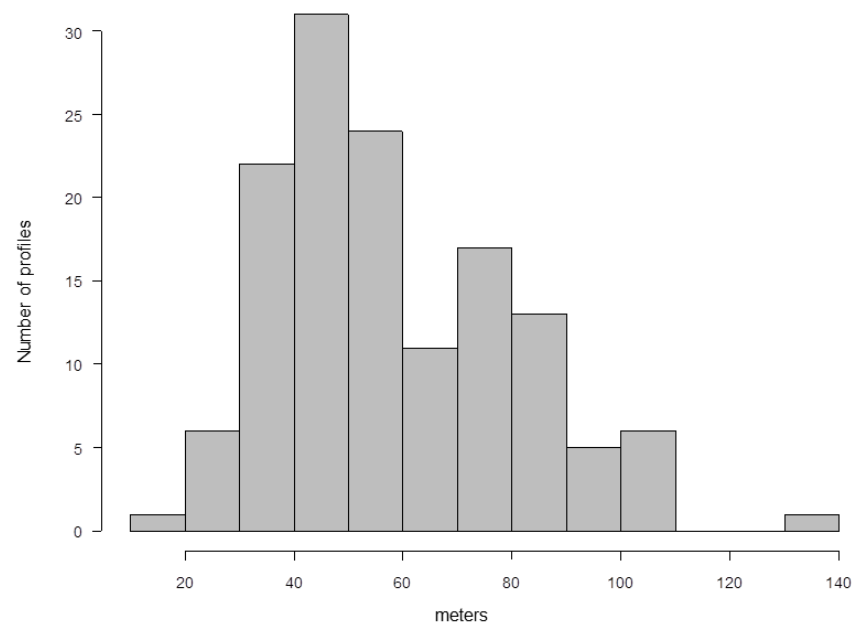

Figure 8. Depth distribution of chl $a$ maxima exceeding $30 \%$ of the surface values.

HPLC measurement or from calibrated fluorometer (Mitchell and Holm-Hansen, 1991; Dierssen and Smith, 2000; HolmHansen et al., 2004; Garcia et al., 2005) with standard algorithms typically underestimating chl $a$ by $2-3$ times (Kahru and Mitchell, 2010) which is consistent with our study, and up to 5 times (Dierssen, 2010). These errors are typically transferred to the estimates of primary production and carbon fluxes.

Therefore, we are confident that the current MODIS data underestimate by a large extent the in situ [chl $a$ ]. In our study the MODIS underestimation was found over the whole study area and, therefore, encompassed a broad range of phytoplankton assemblage. But future studies should investigate in greater details if the relationships between chl $a$ surface concentration estimated from in situ fluorescence measurements and MODIS do vary according to the biogeographic regions of the SO visited by the SES. Furthermore, the in situ chl $a$ /MODIS relationship is characterised by an intercept which is different from 0 . A recent study reveals that within the SO the current ocean colour algorithms significantly underestimate and overestimate chl $a$ at high and low concentrations, respectively (Johnson et al., 2013).

Global estimates of ocean primary production are now based on satellite Ocean Colour data (Longuhurst et al., 1995; Antoine et al., 1996; Behrenfeld and Falkowski, 1997; Behrenfeld et al., 2005). Time series have been built, from which climate-relevant trends can be extracted (Antoine et al., 2005; Polovina et al., 2008; Martinez et al., 2009). In situ and satellite data are highly complementary. Whereas in situ data extend the satellite information into the ocean interior (unseen by the remote sensor) and provide indispensable sea truth data, satellite provides the synoptic coverage.

We also found that when taking into account the quenching effect, deep maxima chl $a$ concentration exceeding $30 \%$ of the surface value were found only in $9 \%$ of the night pro-

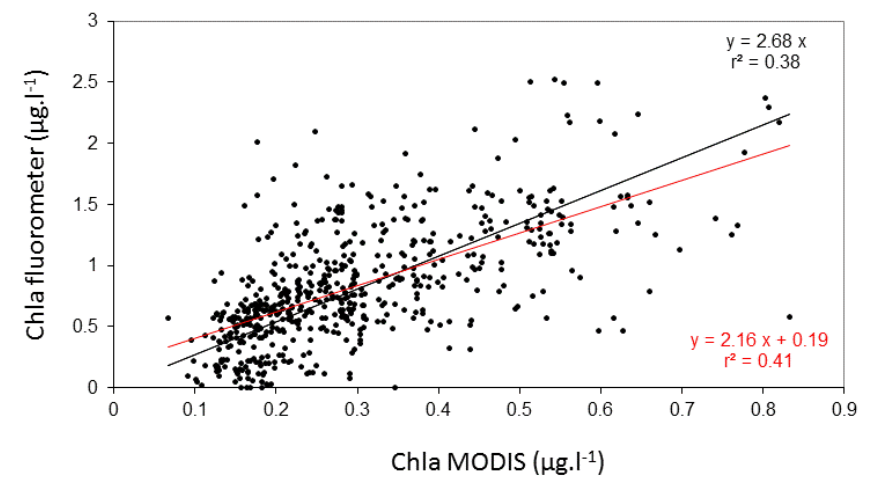

Figure 9. Relationship between the offset, quenching corrected HPLC inter-calibrated fluorometers with the corresponding $9 \mathrm{~km}$ weekly MODIS data. Both regressions with (in red) and without (in black) intercept are presented.

file. According to this result the decoupling of surface and deep phytoplankton biomass observed for only $9 \%$ of the profiles is unlikely to be a major issue when estimating primary production from surface data. However, the real issue is the quenching effect observed during daylight hours and requiring to be properly dealt with (Xing et al., 2012).

Models can only provide useful answers if there are sufficient data to constrain the underlying processes and validate the model output. New approaches to assimilate biological and chemical data into these models are advancing rapidly (Brasseur et al., 2009). Notably, the progressive integration of biogeochemical variables in the next generation of operational oceanography systems is one of the long-term objectives of the GODAE OceanView international programme. Nevertheless, and in view of refining these models for improving their representativeness and predictive capabilities, the datasets currently available remain too scarce. There is an obvious and imperative need to reinforce biological and biogeochemical data acquisition and to organise databases and SES equipped with CTD-Fluo SRDL tags are contributing efficiently to this need.

In situ acquisition of fluorescence data by SES represents a significant contribution to the observation of biogeochemical and ecosystem variables within this undersampled Ocean. These new data implemented in tight synergy with two other essential bricks of an integrated ocean observation system: modelling and satellite observation should represent a significant contribution towards the resolution of important scientific questions relative to the overall phytoplankton biomass and primary production and ultimately changes in carbon fluxes within the SO in relation to climate variability and longer term changes.

\section{Supplementary material related to this article is available online at: http://www.earth-syst-sci-data.net/5/ 15/2013/essd-5-15-2013-supplement.zip.}


Table 2. Correction coefficient calculated for each fluorometer tag (see methods for details). The bold values refer to the correction coefficient applied to the corresponding fluorometer tag, to estimate [chl $a]$.

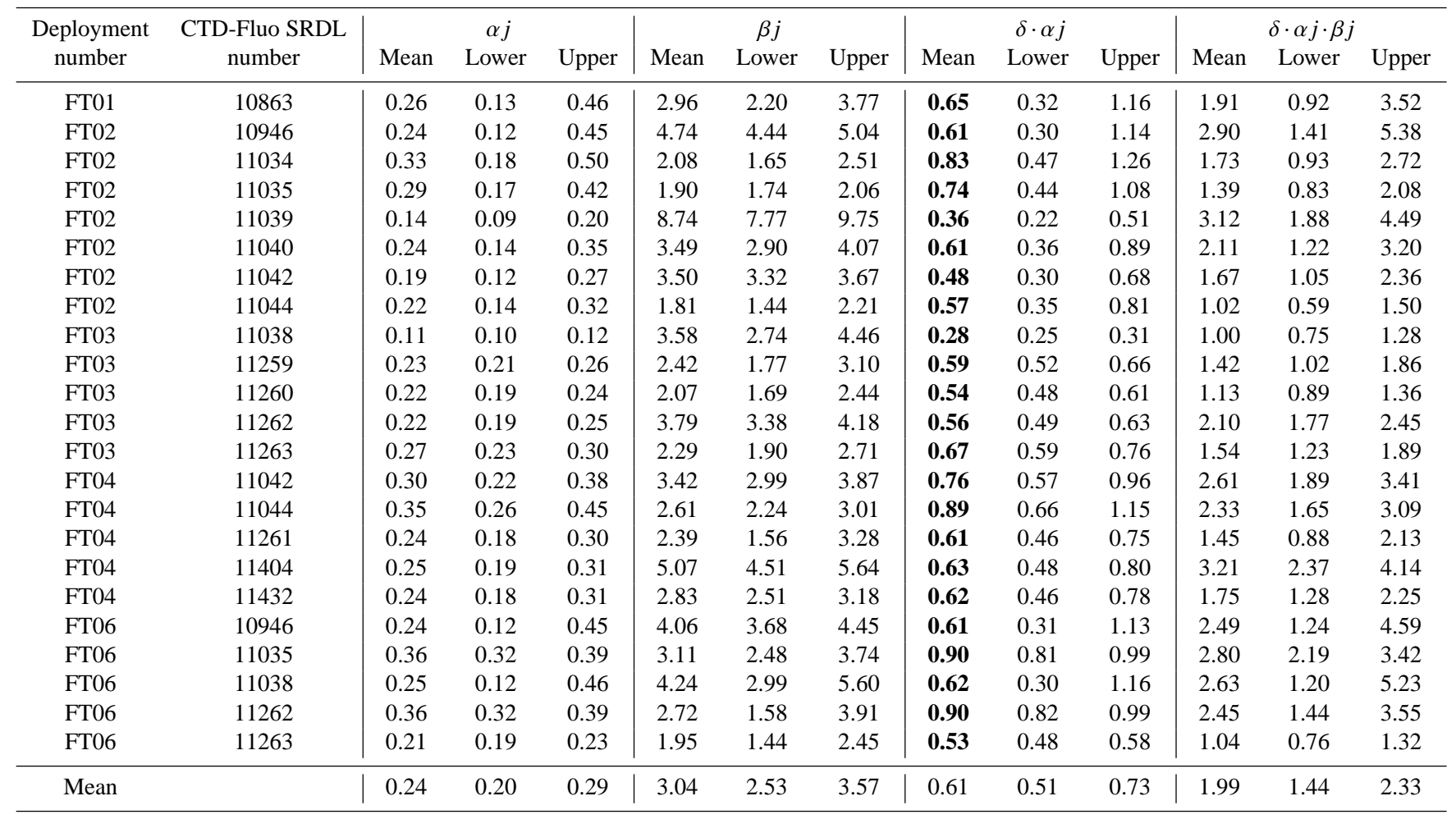

Acknowledgements. This work was supported by CNESTOSCA (Southern Elephant Seal as oceanographer Fluorescence measurements), The MEMO observatory as part of the SOERE CTD-02, the ANR VMC IPSOS-SEAL (2008-2011) and the Total Foundation. We are indebted to IPEV (Institut Polaire Français), for financial and logistical support of Antarctic research program 109 (Seabirds and Marine Mammal Ecology lead by H. Weimerskirch). Special to the BOUSSOLE cruise and team for their help in proceeding at-sea tests and to F. Roquet who proceeded to the correction/validation of the temperature/salinity data. Finally, we would like to thank all the colleagues and volunteers involved in the field work on southern elephant seals at Kerguelen Island, with the special acknowledgement of the invaluable field contribution of N. ElSkaby, G. Bessigneul, A. Chaigne and Q. Delorme.

Edited by: F. Schmitt

\section{References}

Antoine, D., André, J. M., and Morel, A.: Oceanic primary production 2. Estimation at global scale from satellite (coastal zone color scanner) chlorophyll, Global Biogeochem. Cy., 10, 57-69, 1996.

Antoine, D., Morel, A., Gordon, H. R., Banzon, V. F., and Evans R. H.: Bridging ocean color observations of the 1980s and 2000s in search of long-term trends, J. Geophys. Res., 110, C06009, doi:10.1029/2004JC002620, 2005.
Antoine, D., D’Ortenzio, F., Hooker, S. B., Bécu, G., Gentili, B., Tailliez, D., and Scott, A. J.: Assessment of uncertainty in the ocean reflectance determined by three satellite ocean color sensors (MERIS, SeaWiFS, and MODIS-A) at an offshore site in the Mediterranean Sea, J. Geophys. Res., 113, C07013, doi:101029/102007JC004472, 2008.

Argos: User's manual, CLS/Service Argos, Toulouse, 1996.

Arrigo, K. R., Worthen, D. L., Schnell, A., and Lizotte, M. P.: Primary production in Southern Ocean waters, J. Geophys. Res., 103, 587-600, 1998.

Babin, M.: Phytoplankton fluorescence: theory, current litterature and in situ measurements, in: Real-time coastal observing systems for marine ecosystem dynamics and harmful algal blooms, edited by: Babin, M., Roesler, C., and Cullen, J. J., 237-280, Unesco, Paris, 2008.

Babin, M., Morel, A., and Gentili, B.: Remote sensing of sea surface sun-induced chlorophyll fluorescence: Consequences of natural variations in the optical characteristics of phytoplankton and the quantum yield of chlorophyll $a$ fluorescence, Int. J. Remote Sens., 17, 2417-2448, 1996.

Behrenfeld, M. J. and Falkowski, P. G.: Photosynthetic rates derived from satellite-based chlorophyll concentration, Limnol. Oceanogr., 42, 1-20, 1997.

Behrenfeld, M. J. and Kolber, Z. S.: Widespread iron limitation of phytoplankton in the south Pacific Ocean, Science, 283, 840843, 1999.

Behrenfeld, M. J., Boss, E., Siegel, D. A., and Shea, D. M.: Carbon-based ocean productivity and phytoplankton physiology from space, Global Biogeochem. Cy., 19, GB1006, 
doi:10.1029/2004GB002299, 2005.

Behrenfeld, M. J., O’Malley, R. T., Siegel, D. A., McClain, C. R., Sarmiento, J. L., Feldman, G. C., Milligan, A. J., Falkowski, P. G., Letelier, R. M., and Boss, E. S.: Climate-driven trends in contemporary ocean productivity, Nature, 444, 752-755, 2006.

Biuw, M., Boehme, L., Guinet, C., Hindell, M., Costa, D., Charrassin, J. B., Roquet, F., Bailleul, F., Meredith, M., Thorpe, S., Tremblay, Y., McDonald, B., Park, Y.-H., Rintoul, S., Bindoff, N., Goebel, M., Crocker, D., Lovell, P., Nicholson, J., Monks, F., and Fedak, M.: Variations in behaviour and condition of a Southern Ocean top predator in relation to in-situ oceanographic conditions, P. Natl. Acad. Sci. USA, 104, 13705-13710, 2007.

Boehme, L., Meredith, M. P., Thorpe, S. E., Biuw, M., and Fedak, M.: The Antarctic Circumpolar Current frontal system in the South Atlantic: Monitoring using merged Argo and animal-borne sensor data, J. Geophys. Res., 113, C09012, doi:10.1029/2007JC004647, 2008.

Boehme, L., Lovell, P., Biuw, M., Roquet, F., Nicholson, J., Thorpe, S. E., Meredith, M. P., and Fedak, M.: Technical Note: Animalborne CTD-Satellite Relay Data Loggers for real-time oceanographic data collection, Ocean Sci., 5, 685-695, doi:10.5194/os5-685-2009, 2009.

Brasseur, P., Gruber, N., Barciela, R., Brander, K., Doron, M., El Moussaoui, A., Hobday, A. J., Huret, M., Kremeur, A.-S., Lehodey, P., Matear, R., Moulin, C., Murtugudde, R., Senina, I., and Svendsen, E.: Integrating Biogeochemistry and Ecology Into Ocean Data Assimilation Systems, Oceanography, 22, 206-215, 2009.

Buesseler, K. O., Barber, R. T., Dickson, M. L., Hiscock, M. R., Moore, J. K., and Sambrotto, R. N.: The effect of marginal iceedge dynamics on production and export in the Southern Ocean along 170-W, Deep-Sea Res. Pt. II, 50, 579-603, 2003.

Caldeira, K., Hoffert, M. I., and Jain, A.: Simple ocean carbon cycle models, in: The Carbon Cycle, edited by: Wigley, T. M. L. and Schimel, D. S., Cambridge University Press, Cambridge, United Kingdom, 199-211, 2000.

Charrassin, J. B., Hindell, M., Rintoul, S. R., Roquet, F., Sokolov, S., Biuw, M., Costa, D., Boehme, L., Lovell, P., Coleman, R., Timmermann, R., Meijers, A., Meredith, M., Park Y.-H., Bailleul, F., Goebel, M., Tremblay, Y., Bost, C.-A., McMahon, C. R., Field, I. C., Fedak, M. A., and Guinet, C.: Southern ocean frontal structure and sea-ice formation rates revealed by elephant seals, P. Natl. Acad. Sci. USA, 105, 11634-11639, 2008.

Dandonneau, Y. and Neveux, J.: Diel variations of in-vivo fluorescence in the eastern equatorial Pacific an unvarying pattern, Deep-Sea Res., 44, 1869-1880, 1997.

Dierssen, H. M.: Perspective on empirical approaches for ocean color remote sensing of chlorophyll in a changing climate, $\mathrm{P}$. Natl. Acad. Sci. USA, 107, 17073-17078, 2010.

Dierssen, H. M. and Smith, R. C.: Bio-optical properties and remote sensing ocean color algorithms for Antarctic Peninsula waters, J. Geophys. Res., 105, 26301-26312, 2000.

Falkowski, P. G. and Kolber, Z.: Variations in chlorophyll fluorescence yields in phytoplankton in the world oceans, Aust. J. Plant Physiol., 22, 341-355, 1995.

Fedak, M., Lovell, P., McConnell, B., and Hunter, C.: Overcoming the Constraints of Long Range Radio Telemetry from Animals: Getting More Useful Data from Smaller Packages, Integr. Comp. Biol., 42, 3-10, doi:10.1093/icb/42.1.3, 2002.
Field, C. B., Behrenfeld, M. J., Randerson, J. T., and Falkowski, P. G.: Primary production of the biosphere: Integrating terrestrial and oceanic components, Science, 281, 237-240, 1998.

Garcia, C. A. E., Garcia, V. M. T., and McClain, C. R.: Evaluation of SeaWiFS chlorophyll algorithms in the Southwestern Atlantic and Southern Oceans, Remote Sens. Environ., 95, 125137, 2005.

Gelman, A.: Prior Distributions for Variance Parameters in Hierarchical Models (Comment on Article by Browne and Draper), Bayesian Analysis, 1, 515-534, 2006.

Gelman, A., Jakulin, A., Grazia Pittau, M., and Su, Y.-S.: A Weakly Informative Default Prior Distribution for Logistic and Other Regression Models, Ann. Appl. Stat., 2, 1360-1383, 2008.

Hindell, M., Slip, D., and Burton, H.: The diving behaviour of adult male and female southern elephant seals, Mirounga leonina (Pinnipedia: Phocidae), Aust. J. Zool., 39, 595-619, 1991.

Holm-Hansen, O., Kahru, M., Hewes, C. D., Kawaguchi, S., Kameda, T., Sushin, V. A., Krasovski, I., Priddle, J., Korb, R., Hewitt, R. P., and Mitchell, B. G.: Temporal and spatial distribution of chlorophyll-a in surface waters of the Scotia Sea as determined by both shipboard measurements and from satellite data, Deep-Sea Res. Pt. II, 51, 1323-1331, 2004.

Johnson, R., Strutton, P. G., Wright, S., McMinn, A., and Meiners, K. M.: Three Improved Satellite Chlorophyll Algorithms for the Southern Ocean, J. Geophys. Res., submitted, 2013.

Kahru, M. and Mitchell, G. B.: Blending of ocean colour algorithms applied to the Southern Ocean, Remote Sens. Lett., 1, 119-124, 2010.

Kiefer, D. A.: Fluoresence properties of natural phytoplankton populations, Mar. Biol., 22, 263-269, 1973.

Kinkade, C. S., Marra, J., Dickey, T. D., Langdon, C., Sigurdson, D. E., and Weller, R.: Diel bio-optical variability observed from moored sensors in the Arabian Sea, Deep-Sea Res. Pt. II, 46, 1813-1831, 1999.

Krause, G. H. and Jahns, P.: Non-photochemical energy dissipation determined by chlorophyll fluorescence quenching: characterization and function, in: Chlorophyll $a$ Fluorescence: A Signature of Photosynthesis, edited by: Papageorgiou, G. C., and Govindjee, Springer, Dordorecht, The Netherlands, 463-495, 2004.

Lo Monaco, C., Goyet, C., Metzl, N., Poisson, A., and Touratier, F.: Distribution and inventory of anthropogenic $\mathrm{CO}_{2}$ in the Southern Ocean: Comparison of three data-based methods, J. Geophys. Res., 110, C09S02, doi:10.1029/2004JC002571, 2005.

Loftus, M. E. and Seliger, H.: Some limitations of the in vivo fluorescence technique, Chesapeake Sci., 16, 79-92, 1975.

Longhurst, A., Sathyendranath, S., Platt, T., and Caverhill, C.: An estimate of global primary production in the ocean from satellite radiometer data, J. Plankton Res., 17, 1245-1271, 1995.

Lydersen, C., Nøst, O. A., Lovell, P., McConnell, B. J., Gammelsrød, T., Hunter, C., Fedak, M. A., and Kovacs, K. M.: Salinity and temperature structure of a freezing Arctic fjord monitored by white whales (Delphinapterus leucas), Geophys. Res. Lett., 29, 2119, doi:10.1029/2002GL015462, 2002.

Marrari, M., Hu, C., and Daly, K. L.: Validation of SeaWiFS chlorophyll $a$ concentrations in the Southern Ocean: A revisit, Remote Sens. Environ., 105, 367-375, 2006.

Martinez, E., Antoine, D., D’Ortenzio, F., and Gentili, B.: Climatedriven basin-scale decadal oscillations of oceanic phytoplankton, Science, 36, 1253-1256, 2009. 
Mitchell, B. G. and Holm-Hansen, O.: Bio-optical properties of Antarctic Peninsula waters: Differentiation from temperate ocean models. Deep-Sea Res., 38, 1009-1028, 1991.

Nicholls, K. W., Boehme, L., Biuw, M., and Fedak, M. A.: Wintertime ocean conditions over the southern Weddell Sea continental shelf, Antarctica, Geophys. Res. Lett., 35, L21605, doi:10.1029/2008GL035742, 2008.

Polovina, J. J., Howell, E. A., and Abecassis, M.: Ocean's least productive waters are expanding, Geophys. Res. Lett., 35, L03618, doi:10.1029/2007GL031745, 2008.

Quéguiner, B. and Brzezinski, M. A.: Biogenic silica production rates and particulate organic matter distribution in the Atlantic sector of the Southern Ocean during austral spring, Deep-Sea Res. Pt. II, 49, 1765-1786, 2002.

R Development Core Team: R: A Language and Environment for Statistical Computing, R Foundation for Statistical Computing, Vienna, Austria, ISBN 3-900051-07-0, 2002.

Ras, J., Claustre, H., and Uitz, J.: Spatial variability of phytoplankton pigment distributions in the Subtropical South Pacific Ocean: comparison between in situ and predicted data, Biogeosciences, 5, 353-369, doi:10.5194/bg-5-353-2008, 2008.

Reynolds, R. A., Darius, S, and Mitchell, B. G.: A chlorophylldependent semianalytical reflectance model derived from field measurements of absorption and backscattering coefficient within the Southern Ocean, J. Geophys. Res., 10, 7125-7138, 2001.

Roemmich, D., Riser, S., Davis, R., and Desaubies, Y.: Autonomous profiling floats: Workhorse for broad-scale ocean observations, Mar. Technol. Soc. J., 38, 31-39, 2004.

Roquet, F., Park, Y. H., Guinet, C., and Charrassin, J. B.: Observations of the Fawn Trough Current over the Kerguelen Plateau from instrumented elephant seals, J. Marine Syst., 78, 377-393, 2009.

Roquet, F., Charrassin, J. B., Marchand, S., Boehme, L., Fedak, M., Reverdin, G., and Guinet, C.: Validation of hydrographic data obtained from animal-borne satellite-relay data loggers, J. Atmos. Ocean Technol., 28, 787-801, 2011.
Spiegelhalter, D., Best, T., Best, N., and Lunn, D.: Winbugs user manual version 1.4, 2003.

Sturtz, S., Ligges, U., and Gelman, A.: R2winbugs: a Package for Running WinBUGS from R, J. Stat. Softw., 12, 1-16, 2005.

Tokuda, T., Goodrich, B., Van Mechelen, I., Gelman, A., and Tuerlinckx, F.: Visualizing Distributions of Covariance Matrices, Technical report, University of Leuwen, Belgium and Columbia University, USA, available at: http://www.stat.columbia.edu/ $\sim$ gelman/research/unpublished/Visualization.pdf, 2011.

Uitz, J., Claustre, H., Griffiths, B., Ras, J., Garcia, N., and Sandroni, V.: A phytoplankton class-specific primary production model applied to the Kerguelen Isalnds region (Southern Ocean), DeepSea Res. Pt. I, 56, 541-560, 2009.

Waite, A. M. and Nodder, S. D.: The effect of in situ iron addition on the sinking rates and export flux of Southern Ocean diatoms, Deep-Sea Res. Pt. II, 48, 2635-2654, 2001.

Wunsch, C., Heimbach, P., Ponte, R., Fukumori, I., and the ECCOConsortium members: The global general circulation of the oceans estimated by the ECCO-Consortium, Oceanography, 22, 89-103, 2009.

Xing, X., Claustre, H., Blain, S., D’Ortenzio, F., Antoine, D., Ras, J., and Guinet, C.: Quenching correction for in vivo chlorophyll fluorescence measured by instrumented elephant seals in the Kerguelen region (Southern Ocean), Limnol. Oceanogr.-Meth., 10, 483-495, 2012.

Yentsch, C. S. and Menzel, D. W.: A method for the determination of phytoplankton chlorophyll and phaeophytin by fluorescence, Deep-Sea Res., 10, 221-231, 1963.

Yu, X., Dickey, T., Bellingham, J., Manov, D., and Streitlien, K.: The application of autonomous underwater vehicles for interdisciplinary measurements in Massachusettsand Cape Cod Bays, Cont. Shelf Res., 22, 2225-2245, 2002. 